\title{
Knowledge, Attitude, and Practice towards Emergency Contraceptives use Among Negelle Health Sciience College Female Students, South Eastern, Ethiopia: a Descriptive Cross- Sectional Study, 2021
}

\section{GUDISA BEREDA}

Department of pharmacy, Negelle health science college, Guji, Ethiopia

Corresponding Author: Gudisa Bereda, Department of pharmacy, Negelle health science college, Guji, Ethiopia.

Received date: October 19, 2021; Accepted date: December 24, 2021; Published date: January 04,2021

Citation: Gudisa Bereda (2022). Knowledge, Attitude, and Practice towards Emergency Contraceptives use Among Negelle Health Sciience College Female Students, South Eastern, Ethiopia: a Descriptive Cross-Sectional Study, 2021. J.Women Health Care and Issues. 5(1); DOI:10.31579/26429756/093

Copyright: (C) 2022 Gudisa Bereda, This is an open access article distributed under the Creative Commons Attribution License, which permits unrestricted use, distribution, and reproduction in any medium, provided the original work is properly cited.

\section{Abstracts}

Background: Emergency contraceptives is the only method women cause to prevent pregnancy after they have had unprotected sexual intercourse. About $7.2 \%$ of women will be sexually assaulted by a stranger and depending on the region; $23-36 \%$ of women will experience unwanted sex from an intimate partner.

Objective: To ascertain knowledge, attitude and practice towards emergency contraceptive use among female students in Negelle college of health sciences.

Methods: A descriptive cross sectional study design was carried out July 29 /2021 to September 31/2021.Data was collected through employing semi-structured self-administered questioner, and then the collected data was cleared, coded and analyzed by statistical packages for social sciences 26.0 version statistical software. Descriptive statistics were used for variables using statistical parameters of frequencies, and percentages, and were presented in table format. Factors with a bivariate test value $\leq 0.05$ were included.

Results: The study was conducted on total sample of 152 participants, among the respondents, majority $131(86.2 \%)$ of them age was $>20$ years old. Above half $92(60.5 \%)$ of the study subjects was heard the cornerstones merit of contraceptives was to prevent pregnancy.82(53.9) respondents were agree about when having unintended sexual intercourse, they take ECPs.60 (39.5\%) of the study subjects were agree about fear of side effects hinder them from not using ECPs.85(56.0\%) were used EC pills after unprotected sexual intercourse. Age greater than twenty years and unmarred female students was predictors to have good knowledge about EC pills.

Conclusion and recommendations: A majority of this study subjects were came from urban area, and majority of the study subjects were bought EC from pharmacy from pharmacy and shop. Knowledge, attitude and practice towards EC among female students were high. Health care workers should have to escalate awareness of the usage of emergency contraceptive methods among female students.

Keywords: emergency contraceptive; knowledge; attitude and practice; female students; guji; ethiopia

\section{Introduction}

Albert Yuzpe first described the use of hormonal contraception regimen for post coital pregnancy prevention in 1972. Oral contraceptive pills have been used "Off label" for this purpose since that time. According to this approach the medication is taken in two doses. The first within 72 hours of unprotected intercourse and the second 12 hours after the first
[1].Emergency contraception can prevent pregnancy in women at risk of an unintended pregnancy. Also called "morning after" pills or post-coital contraceptives. They are safe for use by all women including those who cannot use ongoing hormonal contraceptive methods, they work by preventing or delaying the release of eggs from the ovaries (ovulation).Women that are already pregnant cannot benefit from ECPs. They do not prevent pregnancy if the sexual intercourse happens more 
than 24 hours after taking ECPs. Without contraception, 8 out of 100 women have the likelihood of becoming pregnant if they have sex once during the second or third week of their menstrual cycle. ECPs are less effective in obese women (body mass index $>30 \mathrm{~kg} / \mathrm{m}^{2}$ ) [2]. However, these women should not be denied the use of emergency contraception when needed. For maximal effectiveness, ECPs should preferably be taken as early as possible after unprotected intercourse and within 72 hours, particularly beneficial to women who want to use a highly effective, long-acting and reversible contraceptive method. Prevent pregnancy by altering the chemical nature of the sperm and egg to stop fertilization. As an emergency contraceptive method, copper-bearing IUD should be inserted within 5 days of unprotected intercourse [3]. Each year there are about 250 Million pregnancies globally and one third of these are unintended and $20 \%$ of these undergo induced abortion. In Low income countries, more than one third of the 182 million pregnancies are unintended; the fate of $19 \%$ will be induced abortion and $11 \%$ of this is unsafe. In low income countries, the women who do not use any contraceptive contribute to two third of unintended pregnancies, where more than 100 million married women have unmet need for contraception [4]. Oral pills and IUCDs are mainly used as EC 72 hours after sexual contact. EC is indicated after unprotected sexual intercourse, following sexual abuse, misuse of regular contraception, or non use of contraception [5].In about half of all unwanted pregnancies, conception occurs due to inadequate guidance to use contraception effectively, including the users' inability to address their feelings, poor attitudes towards contraceptives, and lack of motivations. Despite the Ethiopian government's effort to prevent unwanted pregnancies and abortion among youths of age less than 24 years, the number of youths requesting termination of pregnancy is increasing annually[6].Studies conducted in Ethiopia indicated that awareness of EC is less than $50 \%$ and utilization is below $10 \%$.These limited studies conducted on the issue of EC in the country were mostly focused on university students, who are believed to have better overall knowledge than college students [7].Consequences of unprotected sex, such as unintended pregnancy and unsafe abortion, can be prevented by access to contraceptive services including emergency contraception. Emergency contraception is a method used to avoid pregnancy after unprotected sexual intercourse unlike the regular methods of contraception that are taken before sexual contact. It has the potential, as the last resort, to avoid unwanted pregnancy and therefore abortion; a desirable goal especially when abortion is illegal. Oral contraceptive pills and IUCDs are mainly used as emergency contraceptives. When used within 72 hours after sexual contact pills have the capacity to prevent pregnancy by $75-85 \%$ and with the use of IUCDs unwanted pregnancy can be prevented by as much as $99 \%$. This is especially significant for those young couples that opt not to use a long-term regular contraceptive method and their sexual behavior is rather unplanned, erratic and irregular [8].

Global and regional shows that 14 per 1000 incidence of unsafe and associated mortality in women aged 15 to 44 years in the year 2003 which accounts for $13 \%$ of all maternal deaths worldwide. In east Africa the incidence rate is be 39 per 1000 and accounts for $17 \%$ of all maternal deaths in the region. More than half maternal deaths in Africa are due to unsafe that occurs in age below 25 years of age [9]. Worldwide, around 120 million women per year need contraception but they did not use it. Parallel with this, approximately 250 million pregnancies occur and onethird of them are unintended; out of them, $20 \%$ are terminated by induced abortion. Consequently, around 47,000 women die each year from complications of unsafe abortions [10]In Ethiopia, unwanted pregnancy is a big problem; more than $60 \%$ of the pregnancies in adolescents are unwanted resulting from unprotected sexual intercourse which is an alarming figure, and most of these pregnancies particularly in adolescents end up with unsafe abortion. Unsafe abortion is one of the top causes incriminated in the high number of maternal morbidity and mortality in Ethiopia. According to a national survey on abortion conducted in 2000 by World health organization (WHO), abortion related mortality was 1,209 per 100,000 live births [11].Unwanted pregnancy leading to unsafe abortion is one of the most important causes of maternal morbidity and mortality. Unsafe abortion is a major medical and public health problem in Ethiopia. Ethiopia has a high incidence of unwanted pregnancies and incomplete and unsafe/ septic abortions, particularly among adolescents. Several studies in the country have revealed that women who tend to undergo induced abortion are below the age of 30 years and are literate; many of whom being above the secondary educational level [12]. Unwanted pregnancy and its outward consequences on physical and psychological well being of adolescent girls and young adult women is a problem. Unwanted pregnancy is one of the main factors for unsafe abortion. Every year on average about 210 million throughout the world became pregnant. About 40-50 million of those women result to abortion, 30 million of them are in developing countries. Of 40-50 million abortions performed annually in the world, 20 million are thought to be unsafe [13].Unsafe abortion due to an unplanned pregnancy is one of the main causes of maternal morbidity and mortality in Ethiopian women. Several studies in the country have revealed that women who tend to undergo induced abortions are below the age of 30 and above the secondary educational level. Young people today start sex before marriage. Thus, they face a greater risk of unintended pregnancy[14].This study will be escalate the usage of emergency contraceptive methods which play a crucial role in limiting unwanted pregnancies and ultimately in reducing maternal mortality and morbidity rates.

\section{Methodology}

\section{Study design, settings and participants}

A descriptive cross-sectional study was conducted in ambo preparatory schools from July $29 / 2021$ to September 31/2021. The source population was female students that were included in the sample during data collection. The regular female students in Ambo preparatory schools were included in the study were included in the study. Female students that are not fulfill the inclusion criteria, who had psychiatric history; those unwilling to participate and those of students who were seriously ill were excluded.

\section{Sample size determination and sampling procedure}

The sample size was determined by using the single population proportion formula: The sample size was determined based on"P"value which was taken from Harar Regional State, Eastern Ethiopia, $\mathrm{P}=0.719$, or 71.9, $n=$ $\frac{(Z a / 2) 2 P(1-P)}{d 2}, \mathrm{n}=(1.96)^{2}(1-0.719) \times(0.719) /(0.05)^{2}=310$. Since the total number of female students in our study was less than 10,000 ,reduction formula(correction formula) were applied as follow; $\mathrm{n}_{\mathrm{f}}=$ $\mathrm{n} /(1+(\mathrm{n} / \mathrm{N})), \mathrm{n}_{\mathrm{f}}=310 /(1+(310 / 250)=138$. Non response rate $=10 \%$ (to minimize non response rate $)=138+(138 \times 0.1)=14$. So, the total sample size was=152.A stratified random sampling technique was applied to select the study units. Stratification was done based on year and area of study, and then sample unit was taken by using simple random sampling system. Then the required sample size was selected by lottery method.

\section{Variables of the study}

The dependent variable of the study was knowledge, attitude, and practice towards EC, and independent variable were socio-demographic factors (age, educational status, monthly income, marital status, living condition), year of students at the school, source of information, being sexually active.

\section{Data collection instrument and process}

Data was collected by using face to face self-administered questionnaires which was prepared in English and translated to local language Oromiffa and then translated back to English. The questionnaire contains 5 parts. The first part of the questionnaire includes socio-demographic and socio- 
economic status information such as age, educational status, monthly income, marital status, living condition, the second part shows sources of information for EC \& sources of EC, Part three will the knowledge of emergency contraceptive among female students, Part four will the attitude towards emergency contraceptive among female students, Part five will include practice of EC among female students. Students were informed about the purpose of the study, importance of their participation, and objectives of the study. Verbal consent was obtained from the participant students whom information was obtained.

\section{Data quality assurance}

The questionnaire was developed in English and translated to Oromiffa and back- translation of the guide to English was carried out to ensure the accuracy of the translation. Finally, the questionnaires was gathered and checked for completeness by the principal investigator. The data collected was checked for completeness and consistency on daily basis.

\section{Data organization, presentation, and analysis}

Data was entered and analyzed with statistical packages for social sciences 26.0 version statistical software. Descriptive statistics were used for variables using statistical parameters of frequencies and percentages, and are presented in table format. Both bivariate and multivariate analysis techniques were applied to identify the factors associated with knowledge towards EC. In this model, factors with a bivariate test value $\leq 0.05$ were included.

\section{Ethical considerations}

\begin{tabular}{|l|l|c|c|}
\hline Variables & Category & Frequency & Percent \\
\hline Age & $\leq 20$ years & 21 & 13.8 \\
\cline { 2 - 4 } & $>20$ years & 131 & 86.2 \\
\hline Residency & Urban & 136 & 89.5 \\
\cline { 2 - 4 } & Rural & 16 & 28.3 \\
\hline Marital status & Married & 43 & 71.7 \\
\cline { 2 - 4 } & Unmarried & 109 & 35.5 \\
\hline Religion & Muslim & 54 & 45.4 \\
\cline { 2 - 4 } & Christian & 69 & 19.1 \\
\hline
\end{tabular}

Table 1: Socio-demographic characteristics of female students, NHSC, Southeastern, Ethiopia, 2021.

Source of information and EC toward emergency contraception

Regarding source of information, majority 62(40.8\%) of respondents were acquire information from club in school/friends, and $41(27.0 \%)$ were hear from mass media followed by 23(15.1\%) from parents.
Ethical clearance was obtained from Negelle College of health sciences for this study. During data collection the purpose of study was explained and the verbal consent was obtained from the respondents. Strict behind the scenes was assured through anonymous recording and coding of questionnaires and placed in safe place.

\section{Operational Definitions}

Attitude: Feeling of the people towards emergency contraceptive

Emergency contraceptive: A drug or device used after unprotected sexual intercourse to prevent pregnancy

Knowledge: Familiarity with emergency contraceptives information gained by experience or exposure

Practice: Engagement in sexual activities and utilization of emergency contraceptive.

\section{Results}

Socio-demographic characteristics

In this study out of the total interview guides of sample of 152 participants who were interviewed 152 were included in the analysis, then the response rate was $100 \%$.Most of the respondents were unmarried 109(71.7), and Christians 69(45.4).Among the respondents, majority $131(86.2 \%)$ of them age was $>20$ years old. A majority $136(89.5)$ of our study subjects were came from urban area (Table 1).

\begin{tabular}{|l|l|l|l|}
\hline Variables & Category & Frequency & Percent \\
\hline Source of information & Mass media & 41 & 27.0 \\
\cline { 2 - 4 } & Parents & 23 & 15.1 \\
\cline { 2 - 4 } & Teachers in class & 17 & 11.2 \\
\cline { 2 - 4 } & Health worker education & 62 & 5.9 \\
\cline { 2 - 4 } & Club in school/friends & 62 & 40.8 \\
\hline
\end{tabular}

Majority 58(38.2\%) of the study subjects were bought EC from pharmacy, 56(36.8\%) from pharmacy and shop followed by $31(20.4 \%)$ from governmental health institution, and $53.35 \%$ ) from private clinic (Table 2). 


\begin{tabular}{|l|l|l|c|}
\hline Source of EC & Pharmacy & 58 & 38.2 \\
\hline & Shop & 2 & 1.3 \\
\hline & Private clinic & 5 & 3.3 \\
\cline { 2 - 4 } & Governmental health institution & 31 & 20.4 \\
\cline { 2 - 4 } & Pharmacy and shop & 56 & 36.8 \\
\hline
\end{tabular}

Table 2: Source of information and EC among female students of NHSC, Southeastern, Ethiopia, 2021.

Knowledge of toward emergency contraception

A total of $91(59.9 \%)$ respondents had heard about EC, and majority $67(44.1 \%)$ of the respondents heard about pills types of contraceptives methods followed by 50 (32.9\%).Above half 42(46.2\%) of the study subjects was heard the cornerstones merit of contraceptives was to prevent pregnancy, and $21(23.1 \%)$ prevent sexually transmitted infections. Slightly less than half $36(39.6 \%)$ of participants heard contraceptives mostly required during raped followed by $31(34.1 \%)$ when condom breaks. A majority 39(42.9\%) of respondents heard the recommended time to take ECPs was within 72 hours after sex, and 41(45.1\%) heard the recommended number of dose was two. Above half 44(48.3\%) of study subjects were heard the recommended time between the doses was 12 hours apart, and 51(33.6\%) respondents had heard about IUDs, and $23(45.2 \%)$ heard the recommended time for IUCD on emergency contraception was within 5 day after sex (Table 3 ).

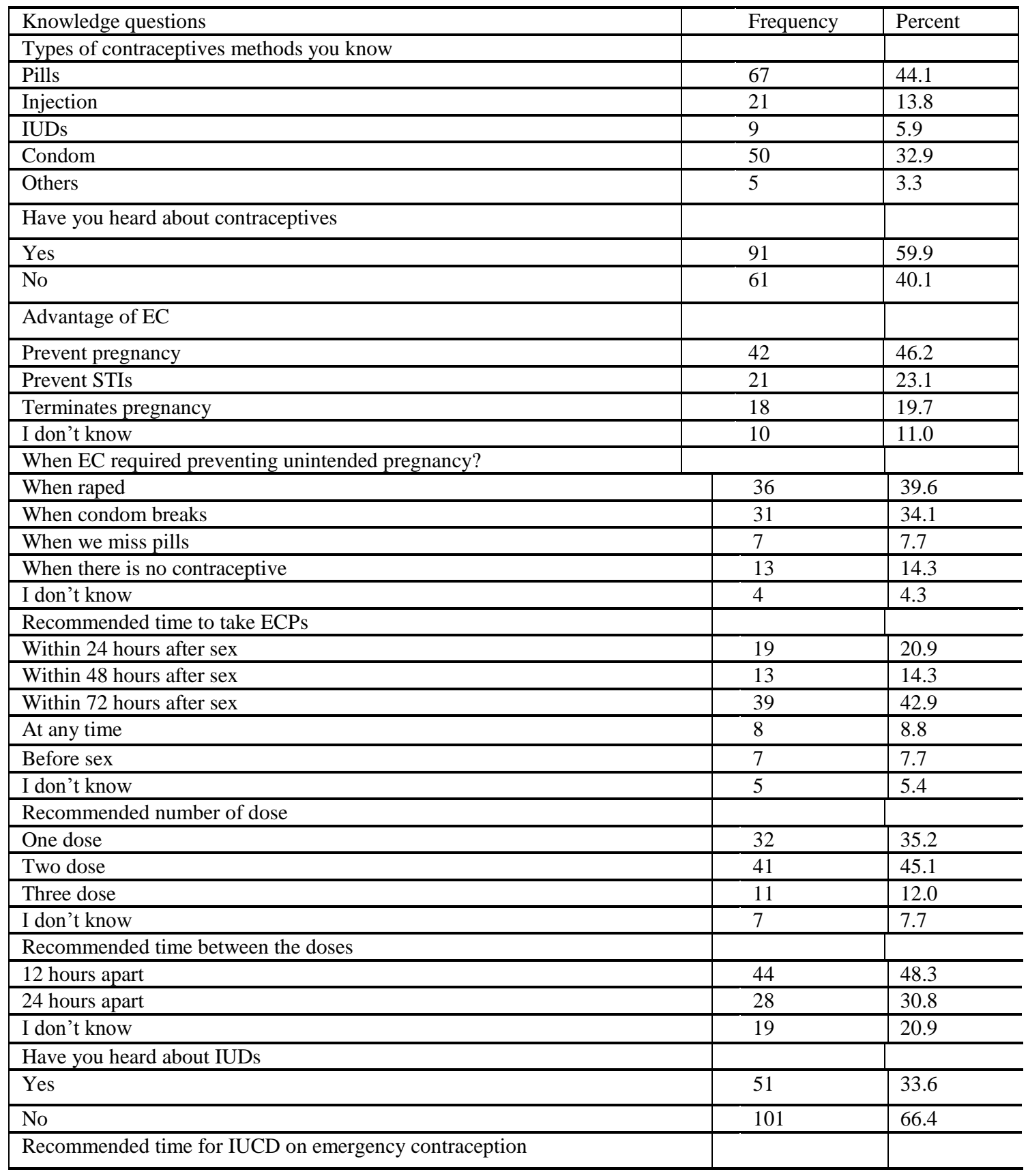




\begin{tabular}{|l|c|c|}
\hline Within 24 hours after sex & 9 & 17.6 \\
\hline Within 72 hours after sex & 12 & 23.5 \\
\hline Within 5 day after sex & 23 & 45.2 \\
\hline I don't know & 7 & 13.7 \\
\hline
\end{tabular}

Table 3: Knowledge of EC among Female students of NHSC, South eastern, Ethiopia, 2021.

Attitudes toward emergency contraception

A total of $74(48.7 \%)$ of respondents were agree about increased accessibility of EC make women stop using other forms of contraceptive, and $57(37.5 \%)$ participants were agree that EC methods limited because they could have side effects. Majority $59(38.8 \%)$ of respondents were disagree that EC methods have an effect on future fertility, and 82(53.9\%) respondents were agree about when having unintended sexual intercourse, they take ECPs. Half 75(49.3\%) of study subjects were disagree that wide spread use of ECPs increase the prevalence of HIV/AIDS and other STIs, and $56(36.8 \%)$ of respondents were disagree about advising close friend or relative have unintended sexual inter course to take ECPs. Above half $79(52.0 \%)$ participants were agree that use emergency contraception promotes promiscuity, and only $27(17.8 \%)$ respondents were agree that emergency contraception is one way of abortion. $60(39.5 \%)$ of the study subjects were agree about fear of side effects hinder you from not using ECPs, and only, 33(21.7\%) participants were agree that emergency contraception affect ongoing regular methods of contraception negatively (Table 4).

\begin{tabular}{|c|c|c|c|}
\hline \multirow[t]{2}{*}{ Attitude idea } & I agree & Neutral & I disagree \\
\hline & $\mathrm{N}(\%)$ & $\mathrm{N}(\%)$ & $\mathrm{N}(\%)$ \\
\hline $\begin{array}{l}\text { Increased accessibility of EC make women stop using other forms of } \\
\text { contraceptive }\end{array}$ & $74(48.7)$ & $36(23.7)$ & $42(27.6)$ \\
\hline EC methods limited because they could have side effect & $57(37.5)$ & $49(32.2)$ & $46(30.3)$ \\
\hline EC methods have an effect on future fertility & $48(31.6)$ & $45(29.6)$ & $59(38.8)$ \\
\hline If you have unintended sexual intercourse, would you use ECPs & $82(53.9)$ & $29(19.1)$ & $41(27.0)$ \\
\hline $\begin{array}{l}\text { Close friend or relative have unintended sexual inter course would you } \\
\text { advice her to use ECPs }\end{array}$ & $55(36.2)$ & $41(27.0)$ & $56(36.8)$ \\
\hline $\begin{array}{l}\text { Wide spread use of ECPs increase the prevalence of HIV/ AIDS and } \\
\text { other STIs }\end{array}$ & $26(17.1)$ & $51(33.6)$ & $75(49.3)$ \\
\hline Use emergency contraception promotes promiscuity & $79(52.0)$ & $22(14.5)$ & $51(33.5)$ \\
\hline Emergency contraception is one way of abortion & $27(17.8)$ & $62(40.8)$ & $63(41.4)$ \\
\hline Fear of side effects hinder you from not using ECPs & $60(39.5)$ & $53(34.9)$ & $39(25.6)$ \\
\hline $\begin{array}{l}\text { Emergency contraception affect ongoing regular methods of } \\
\text { contraception negatively }\end{array}$ & $33(21.7)$ & $61(40.1)$ & $58(38.2)$ \\
\hline
\end{tabular}

Table 4: Attitude of EC among Female students NHSC, South eastern, Ethiopia, 2021.

Practice of emergency contraceptives

A majority 53(34.9\%) of participants were don't used EC due to privacy not kept and others, and 45(29.6\%) fear of stigma followed by 31(20.4\%) I do not want to use. Greater than half $92(60.5 \%)$ of participants were use EC within 72 hours if they had sexual intercourse accidentally, and
$112(73.7 \%)$ respondents were take EC tablet two times after sexually intercourse. Half $79(52.0 \%)$ of the study subjects were used EC after heard from friend/male, followed by $57(37.5 \%)$ heard from friend/female, and $85(56.0 \%)$ were used EC pills after unprotected sexual intercourse (Table 5).

\begin{tabular}{|l|c|c|}
\hline Practice opinions & Frequency & Percent \\
\hline What makes you not using EC & & \\
\hline I do not know about EC availability & 23 & 15.1 \\
\hline Fear of stigma & 45 & 29.6 \\
\hline Privacy not kept and others & 53 & 34.9 \\
\hline I do not want to use & 31 & 20.4 \\
\hline When EC you used & & \\
\hline Within 72 hours & 92 & 60.5 \\
\hline Within 24 hours & 43 & 28.3 \\
\hline I do not know & 17 & 11.2 \\
\hline How many time EC you used & & \\
\hline Once & 40 & 26.3 \\
\hline Twice & 112 & 73.7 \\
\hline Who told you to use EC & & \\
\hline Friend/female & 57 & 37.5 \\
\hline Friend/male & 79 & 52.0 \\
\hline Health worker & 16 & 10.5 \\
\hline What you do after unprotected sexual intercourse? & & \\
\hline
\end{tabular}




\begin{tabular}{|l|l|l|}
\hline Terminate the pregnancy & 29 & 19.1 \\
\hline I do nothing & 20 & 13.2 \\
\hline Use EC pills & 85 & 56.0 \\
\hline I don't know & 18 & 11.7 \\
\hline
\end{tabular}

Table 5: Practice of EC among female students of NHSC, South eastern, Ethiopia, 2021

Binary logistic regressions associated with knowledge of EC among female students

Only socio-demographic factors were associated statistically with knowledge about EC. From that age $>20$ years female students were 4.63more likely to have good knowledge about $\mathrm{EC}(\mathrm{AOR}=4.63,95 \% \mathrm{CI}$ : 3.861-9.15, $\mathrm{p}=0.006$ ) than their counterparts, and unmarried female students were 2.9 6more likely to have good knowledge about EC $(\mathrm{AOR}=2.96,95 \% \mathrm{CI}: 2.825-3.176, \mathrm{p}=0.047)$ than married female students (Table 6).

\begin{tabular}{|l|l|l|l|c|}
\hline Variable & Category & $\mathrm{N}(\%)$ & AOR (95\% C.I & p-value \\
\hline Age & $\leq 20$ years & $21(13.8)$ & References & 0.006 \\
\cline { 2 - 5 } & $>20$ years & $131(86.2)$ & $4.63(3.861-9.153)$ & 0.17 \\
\hline Residency & Urban & $16(10.5)$ & References & 0.047 \\
\cline { 2 - 5 } & Rural & $136(89.5)$ & $1.25(1.035-1.429)$ & \\
\hline Marital status & Married & $43(28.3)$ & References & 0.74 \\
\cline { 2 - 5 } & Unmarried & $109(71.7)$ & $2.96(2.825-3.176)$ & 0.076 \\
\hline
\end{tabular}

Table 6: Socio-demographic factors associated with knowledge towards EC among female students of NHSC, South eastern, Ethiopia, 2021.

\section{Discussion}

Nowadays, ECPs have become more available in many developing countries. However, limited awareness and knowledge, as well as limited access, have hindered unmarried women from learning about ECPs, and using them worldwide, approximately 40 percent of the pregnancies ( 85 million) were unintended. Women with unintended pregnancy may face the choice between terminating the pregnancy or allowing unwanted birth [15]. Many of which are performed in unsafe conditions and others carry their pregnancies to term, incurring the risk of morbidity and mortality higher than those for adult women [16]. Emergency contraception is most useful when there is a failure of barrier methods such as slippage and breakage of condoms, or when sexual intercourse was unpremeditated [17].

The present study shown $71.7 \%$ of the respondents were unmarried and $89.5 \%$ of this study subjects were came from urban area was dissimilar with the study conducted in Women Seeking Induced Abortion in Public Hospitals, Eastern Tigray [18] showed the respondents' age was from 16 to 47 years old with mean and standard deviation of 25.2 26.95 .Fifty-three percent of the respondents were rural dwellers. The differences was majority of this study subjects were lived in urban area, so there was no more socio economic problems as rural area which makes female married at teenage.

In current study $60.5 \%$ of the study subjects was heard the cornerstones merit of contraceptives was to prevent pregnancy was higher than the survey done in Dire Dawa 34.1\%,Egypt 24.5\%,Nepal 47\%,South Africa $42 \%[19,20,21,22,23]$.Because this survey was fully done on the health sciences students, so they had enough information about ECPs. This study was less than the study conducted in Ghana $69 \%$, Mexico $72.3 \%$, Hong Kong $70 \%$ and Canada $80 \%$ [24, 25, 26, 27].The differences was in this study the access to family planning service of the reproductive rights of women and the tools used to prevent unintended pregnancy was low due to the students had have no plan to bring forth the children. The present study was in line with survey employed in Adama University 62.9\%, Jimma University 58.9\%, Debre Markos 62.5\% [28, 29, 30].Because of the study under taken on the similar study subjects, respondents who had adequate information about the ECPs.
The current study revealed that $44.1 \%$ of the respondents heard about pills types of contraceptives methods followed by $32.9 \%$ were consistent with the survey done in among Female Dangila Hidase High School Students [31] which showed utilization of contraceptive pills after unprotected sexual intercourse was the most widely known method. Because pills type of ECPs was easily accessible and not need skilled trainer to administer.

Regarding source of information, majority $40.8 \%$ of this respondents were acquire information from club in school/friends, and $27.0 \%$ were hear from mass media followed by $15.1 \%$ from parents was inconsistent with the survey employed in among Female Dangila Hidase High School Students [30] which showed the most common source of information was health workers $(58.9 \%)$ followed by school $(18.9 \%)$.Due to health care workers in this study perhaps not eager to counsel health sciences students due wrong perception, and majority of them hear from each others in tutelage place.

The present study revealed that $75(49.3 \%)$ of study subjects were disagree that wide spread use of ECPs increase the prevalence of HIV/AIDS and other STIs,52.0\%) participants were agree that use emergency contraception promotes promiscuity, and $21.7 \%$ ) participants were agree that emergency contraception affect ongoing regular methods of contraception negatively were connate with the survey done in Jimma University [29] showed that wide spread use of ECs will increase the prevalence of HIV/AIDS and other STIs, emergency contraception promotes promiscuity, and emergence contraception will affect regular methods of contraception negatively. Because ECPs perhaps substantially elevated risk for HIV infections due to ECPs users perhaps didn't take care of themselves.

The current study showed $53.9 \%$ respondents had positive attitude towards ECPs was lower than the study conducted in Atse Yohanesse preparatory School, Mekelle $64.9 \%$, Adama University $62.9 \%$ [31, 28] of them had a positive attitude. Becatuse of majority of them had no participate in sexual intercourse. This study was in line with the survey employed in Addis Ababa University 53\%, Bahir Dar University 56.7\% $[32,33]$.Due likewise study area. 
The prevalence of practice of ECs among sexually active respondents in this study was found to be $56.0 \%$ was higher than study done in Mexico $16.4 \%$, Scotland $31.4 \%$. Because this study may comparable with the study done in Atse Yohanesse preparatory School, Mekelle 53.5\%[31]. This study was lower than the survey done in $73.4 \%$ in Bahir Dar University, $75 \%$ in Addis Ababa University. Because of sample size was differences.

The knowledge of the respondents regarding the correct time for taking ECs in this study $(60.5 \%)$ was lower than the survey conducted in Atse Yohanesse preparatory School, Mekelle 67.4\%[31].Because our study subjects used not only ECPs but also condoms. The present study was higher than the survey done in Scotland (26.4\%) [34], in Nepal 9.58\% [22].Due to variations of the study subjects.

The current study revealed that age $>20$ years female students were 4.63more likely to have good knowledge about EC $(\mathrm{AOR}=4.63,95 \% \mathrm{CI}: 3.861-9.15, \mathrm{p}=0.006)$ than their counterparts ,and unmarried female students were 2.96 more likely to have good knowledge about EC $(\mathrm{AOR}=2.96,95 \% \mathrm{CI}: 2.825-3.176, \mathrm{p}=0.047)$ than married female students were inconsistent with the survey conducted in Jimma University[29] showed respondents from medical and public health faculty and urban area were more likely to have heard of ECs. Because of unmarried female students was fear pregnancy and social stigma.

\section{Conclusion and recommendations}

A majority of this study subjects were came from urban area, and majority of the study subjects were bought EC from pharmacy and shop followed by from governmental health institution, and from private clinic. Slightly less than half of participants heard contraceptives mostly required during raped followed by when condom breaks. A total of respondents were agree about increased accessibility of EC make women stop using other forms of contraceptive, and participants were agree that EC methods limited because they could have side effects. A majority of participants were done used EC due to privacy not kept and others, and fear of stigma followed by I do not want to use. Knowledge, attitude and practice towards EC among female students were high. Age greater than twenty years and unmarred female students was predictors to have good knowledge about EC. Health care workers should have to escalate awareness of the usage of emergency contraceptive methods among female students.

\section{Acknowledgments}

We extend our gratitude to the study subjects and data collectors.

\section{Conflict of interest}

No conflict of interest

\section{Funding}

None

\section{References}

1. Ahmedet al.Assessing knowledge, attitude, and practice of emergency contraception: a cross-sectional study among Ethiopian undergraduate female students.BMC Public Health 2012, 12:110.

2. World Health Organization.Emergency contraception:Key facts [Internet].WHO;20 18Feb02[cited2018Oct27].

3. World Health Organization Department of Reproductive Health and Research (WHO/RHR) and Johns Hopkins Bloom berg School of Public Health/Center for Communication Programs (CCP),Knowledge for Health Project. Family Planning:A Global Handbook for Providers (2018 update).Baltimore and Geneva:CCP and WHO;2018.
4. M.Abate,N.Assefa, and

T.Alemayehu,"Knowledge, attitude,practice, and determinant $\mathrm{s}$ emergency contraceptive use among women seeking abortion services in Dire Dawa, Ethiopia,'PLoS One,vol.9,no.10,Article ID e110008,2014.

5. J.L.Lenjisa,Z.Gulila, and N.Legese,"Knowledge, attitude and practice of emergency contraceptives among ambo university female students, West Showa,Ethiopia," Rese arch Journal of Pharmaceutical Sciences,vol.2,no.11,pp.1-5,2013

6. Kayogoza J Byamugisha. User and provider perspectives emergency contraception among young people in Uganda,2007,Kampala and Stockholm (PHD thesis)

7. J.L.Lenjisa,M.A.Woldu,and D.Ulfna, "Knowledge,Attitude and Practice of Emergen cy Contraceptives among Ambo TVET College Female Students,Ethiopia,'IJMCH, vol.16,no.1,pp.1$11,2014$.

8. Friedman S,McQuaid,Grendell J.Current obstetric \& gynecology diagnosis \& treatment:9thEdition;2003

9. World Health Unsafe Global and regional of incidence of unsafe an associated mortality in 2007. (5th eds)

10. J.Benson,K.Andersen, and G.Samandari,"Reductions in abortionrelated mortality following policy reform:evidence from Romania,South Africa and Bangladesh," Repr oductive Health,vol.8,no.1,2011

11. Seife M.Fikre E.Assessment of level of awareness and utilization of emergency contraception,among college female students in Oromia Regional state,Arsi Zone, Asella,South East Ethiopia.June,2007,(Master thesis).

12. Melkamu Y,Enquselassie F,Ali A,et.al.Fertility awareness and future pregnancy int ention of post abortion patients in Addis Ababa,Ethiopia.Eth J Health Dev 2003;17 (3):167-174.

13. S.SinghandE.J.Darroch,AddingItUp:The Costs and Benefits of Contraceptive Servi ces;Estimates for 2012,Guttmacher Institute,New York,NY,USA,2012.

14. Y.Berhan and A.Berhan,"Causes of maternal mortality in Ethiopia:a significant de cline in abortion related death,"Ethiopian Journal of Health Sciences, vol.24,pp.15-28, 2014

15. Family Health Adolescents and Emergency Pills in Developing Countries FHI Wo rking Paper Series No.WP05-01.2005

16. Desta B,Regassa N.(2001).On emergency contraceptive among female students of Haramaya University,Ethiopia:surveying the level of knowledge and attitude.Int Res J 2: 1106-1117.

17. Barb ara E.K Rogers W.Rochal and Widad K.Maternal mortality in Addis Ababa. Ethiopia studies in family planning 1986;17 $(6 / 1): 288-301$

18. Abraha D.et al.Knowledge of and Utilization of Emergency Contraceptive and Its Associated Factors among Women Seeking Induced Abortion in Public Hospitals, Eastern Tigray, Ethiopia, 2017:A Cross-Sectional Study.BioMed Research Interna tional Volume 2019,Article ID 7209274,7 pages

19. M.Abate,N.Assefa, and T.Alemayehu, "Knowledge, attitude,practice, and determin ants emergency contraceptive use6 BioMed Research International among women seeking abortion services in Dire Dawa,Ethiopia,"PLoS One,vol.9,no.10,Article ID e 110008, 2014.

20. H.A.El-Sabaa,A.F.Ibrahim, and W.A.Hassan, “Awareness and use of emergency contraception among women of childbearing age at the family health care centers in Alexandria, Egypt,"Journal of Taibah University Medical Sciences,vol.8,no.3,pp.167 $172,2013$.

21. Subedis S.(2012).Knowledge, attitude and practice on emergency contraceptives among youth of parabat district. JHAS. 2:50-53.

22. L.Myer,R.Mlobeli,D.Cooper,J.Smit,and C.Morroni,"Knowledge and use of emerge ncy contraception among women in the western 
Cape province of South Africa: a cross sectional study,'BMC Women's Health,vol.7,no.1,2007.

23. A.Amalba,V.Mogre,M.N.A.Appiah, and

W.A.Mumuni,"Awareness, use and associated factors of emergency contraceptive pills among women of reproductive age (15- 49years) in Tamale,Ghana," BMC Women's Health,vol.14,no.1,2014.

24. Walker DM,Torres P,Gutierrez JP,Flemming K,Bertozzi SM.(2004).Emergency Contraception Use Is Correlated with Increased Condom Use among Adolescents: Results from Mexico.J Adolesc Healt.35:329-334.

25. Lee S,Wai M, Lai L,Ho P.Women's knowledge and attitudes towards emergency contraception in Hong Kong:Questionnaire survey.Hong Kong Medical Journal,1999; 5:349-352.

26. Langille DB,Delaney ME.(2000).Knowledge and Use of Emergency Postcoital Contraception by Female Students at a High School in Nova Scotia.Can J Public Heal th.91:29-32.

27. Tilahun D,Assefa T,Belachew T.awareness, knowledge and utilization of emerge ncy contraceptives among Adama University female students.Ethiop J Health Sci.Vo 1. 20,No.3 November 2010

28. Tajure N.knowledge,attitude and practice of emergency contraception among grad uating female students of Jimma
University South west,Ethiopia..Ethiop J Health Sci. Vol.20,No.2 July 2010

29. Dagnachew A.Assessment of Knowledge,Attitude and Practice of Emergency Con traceptive Use among Female Students in Harar Preparatory Schools,Harar Regional State,Eastern Ethiopia.Dagnachew,Reprod Syst Sex Disord 2017,6:4DOI:10.4172 /2161-038X.1000215

30. Abrha S,Zeratsion F,Molla F,Eticha $\mathrm{T}$ et al.Assessment of Knowledge,Attitude and Practice among Regular Female Preparatory School Students towards Emergency Contraceptives in Mekelle,Northern Ethiopia.Solomon Abrha et al./ International Jour nal of Pharma Sciences and Research (IJPSR).ISSN:09759492.Vol.5.No.11Nov 2014

31. Tamire W,Enqueselassie F.Knowledge,attitude, and practice on emergency contra ceptives among female university students in Addis Ababa,Ethiopia.Ethiop.J.Health Dev.2007;21;(2):111-116

32. Zeleke G,Zemenay Z,Weldegerima B.(2009).Knowledge,Attitude and Practice of Emergency Contraception among female Bahir Dar University Students,Northwest Ethiopia.Eth J Rep Health.3:59-64.

33. Graham A,Green L,Glasier AF.(1996).Teenagers' knowledge of emergency contra ception:questionnaire survey in south east Scotland.BMJ.312:1567-1569
This work is licensed under Creative Commons Attribution 4.0 License

\section{Submit Manuscript}

Ready to submit your research? Choose Auctores and benefit from:

$>$ fast, convenient online submission

$>$ rigorous peer review by experienced research in your field

$>$ rapid publication on acceptance

$>$ authors retain copyrights

$>$ unique DOI for all articles

$>$ immediate, unrestricted online access

At Auctores, research is always in progress.

Learn more https://auctoresonline.org/journals/women-health-care-and-issues-

DOI: $10.31579 / 2642-9756 / 097$ 